\title{
Percentage Distribution of Deaths Involving Injuries from Recreational and Nonrecreational Use of Watercraft, * by Month — United States, 2015-2017
}

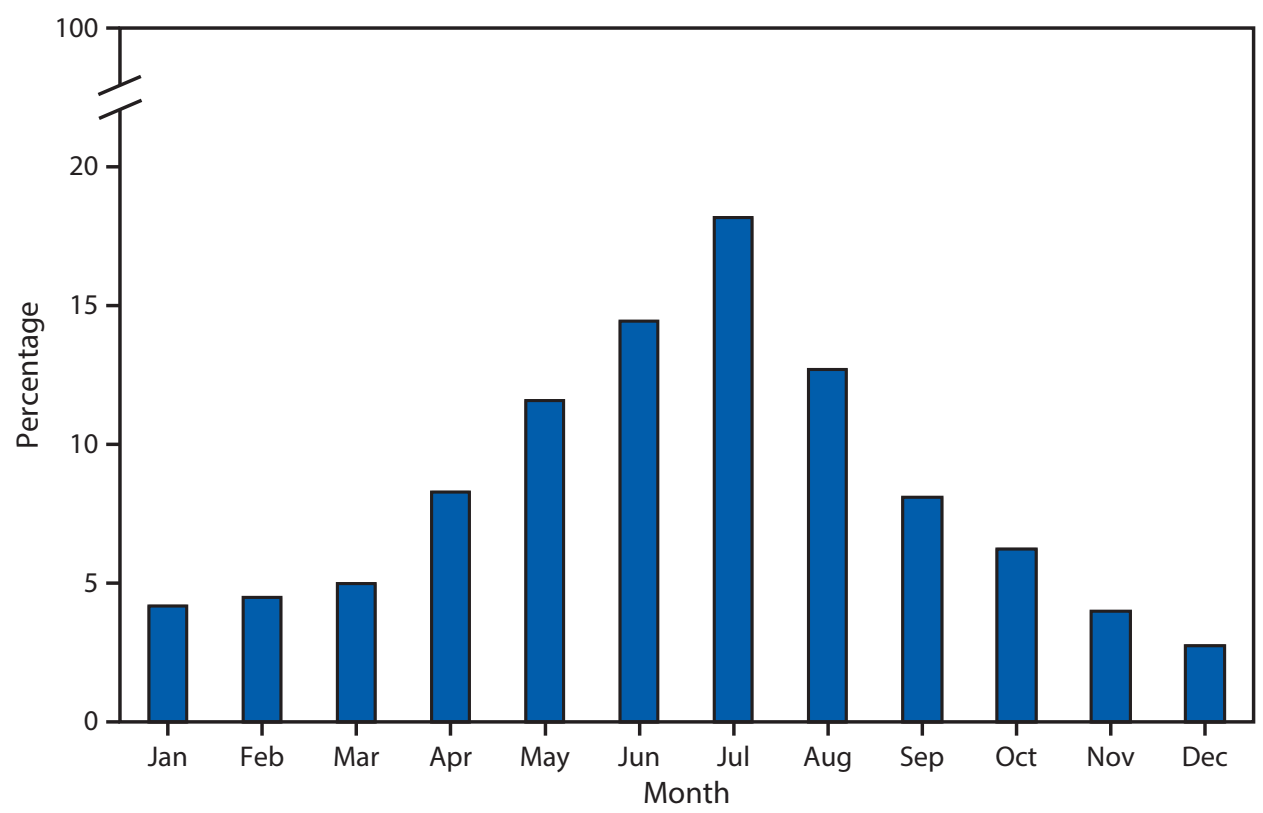

\footnotetext{
* During 2015-2017, there were 1,389 deaths involving injuries from recreational and nonrecreational use of watercraft. Deaths were identified using International Classification of Diseases, Tenth Revision (ICD-10) underlying cause of death codes V90-V94 (water transport). Water transport includes both recreational and nonrecreational use of motorized (e.g., merchant ship, ferry, passenger ship, fishing boat, and jet ski) and nonmotorized (e.g., canoe, kayak, inflatable craft, surfboard, and windsurfer) watercraft. Deaths resulted from drowning, submersion, and other types of injuries. All water transport deaths are unintentional.
}

During 2015-2017, there were 1,389 deaths involving injuries from recreational and nonrecreational use of watercraft (an average of 463 deaths per year). The percentage of deaths that occurred by month ranged from $2.7 \%$ in December to $18.2 \%$ in July. The majority of deaths (57\%) occurred during May-August.

Source: National Center for Health Statistics, National Vital Statistics System, Mortality File. http://www.cdc.gov/nchs/nvss/deaths.htm. Reported by: Holly Hedegaard, MD, hdh6@cdc.gov, 301-458-4460. 